OPEN ACCESS

Edited by:

Giovanna Suzzi,

University of Teramo, Italy

Reviewed by:

Soner Soylu,

Mustafa Kemal University, Turkey

Rosanna Tofalo,

University of Teramo, Italy

${ }^{*}$ Correspondence:

Viviana A. Rapisarda

vrapisarda@fbqf.unt.edu.ar

Specialty section:

This article was submitted to

Food Microbiology,

a section of the journal

Frontiers in Microbiology

Received: 22 December 2016

Accepted: 20 February 2017

Published: 07 March 2017

Citation:

Olmedo GM, Cerioni L, González MM, Cabrerizo FM, Volentini SI and Rapisarda VA (2017) UVA Photoactivation of Harmol

Enhances Its Antifungal Activity against the Phytopathogens Penicillium digitatum and Botrytis cinerea. Front. Microbiol. 8:347. doi: 10.3389/fmicb.2017.00347

\section{UVA Photoactivation of Harmol Enhances Its Antifungal Activity against the Phytopathogens Penicillium digitatum and Botrytis cinerea}

\author{
Gabriela M. Olmedo', Luciana Cerioni' ${ }^{1}$, María M. González², Franco M. Cabrerizo², \\ Sabrina I. Volentini ${ }^{1}$ and Viviana A. Rapisarda ${ }^{1 *}$
}

' INSIBIO (CONICET, UNT), Instituto de Química Biológica "Dr. Bernabé Bloj", Facultad de Bioquímica, Química y Farmacia, UNT, Tucumán, Argentina, ${ }^{2}$ IIB-INTECH - UNSAM-CONICET, Buenos Aires, Argentina

Phytopathogenic fungi responsible for post-harvest diseases on fruit and vegetables cause important economic losses. We have previously reported that harmol (1-methyl$9 \mathrm{H}$-pyrido[3,4-b]indol-7-ol) is active against the causal agents of green and gray molds Penicillium digitatum and Botrytis cinerea, respectively. Here, antifungal activity of harmol was characterized in terms of $\mathrm{pH}$ dependency and conidial targets; also photodynamic effects of UVA irradiation on the antimicrobial action were evaluated. Harmol was able to inhibit the growth of both post-harvest fungal disease agents only in acidic conditions ( $\mathrm{pH}$ 5), when it was found in its protonated form. Conidia treated with harmol exhibited membrane integrity loss, cell wall disruption, and cytoplasm disorganization. All these deleterious effects were more evident for $B$. cinerea in comparison to $P$. digitatum. When conidial suspensions were irradiated with UVA in the presence of harmol, antimicrobial activity against both pathogens was enhanced, compared to non-irradiated conditions. B. cinerea exhibited a high intracellular production of reactive oxygen species (ROS) when was incubated with harmol in irradiated and non-irradiated treatments. P. digitatum showed a significant increase in ROS accumulation only when treated with photoexcited harmol. The present work contributes to unravel the antifungal activity of harmol and its photoexcited counterpart against phytopathogenic conidia, focusing on ROS accumulation which could account for damage on different cellular targets.

\section{Keywords: $\beta$-carboline, alkaloids, photosensitization, reactive oxygen species, cellular damage}

\section{INTRODUCTION}

Several pre- and post-harvest diseases are caused by the attack of the phytopathogenic fungus Botrytis cinerea in more than 200 plant species (Elad and Evensen, 1995). Other fungus that has adverse effects on crop yields and quality is Penicillium digitatum, the causal agent of green mold, the most common post-harvest disease of citrus fruit (Holmes and Eckert, 1999). In agricultural 
practices, fungicides such as imazalil, thiabendazole and dicarboximide, are extensively used to control diseases provoked by these fungi. The continuous use of commercial fungicides has resulted in environmental contamination and the appearance of resistant strains of both phytopathogens (Latorre et al., 1994; Palou et al., 2002). The discovery of antimicrobial compounds to control fungal diseases of economic importance in agriculture remains a major scientific challenge. In this regard, natural products isolated from plants are continuously being evaluated for their antimicrobial activity and result in promising alternatives to commercial fungicides (Grayer and Kokubun, 2001; Soylu et al., 2010; Gatto et al., 2011; Sayago et al., 2012).

$\beta$-carbolines $(\beta C s)$ comprise a class of alkaloids that are widely distributed in nature, including plants, foodstuffs, marine creatures, insects, mammalians, human tissues and body fluids. $\beta \mathrm{Cs}$ are a large group of heterocyclic compounds with a $9 \mathrm{H}$ pyrido[3,4-b]indole structural unit (Gonzalez et al., 2009a) that were originally isolated from Peganum harmala (Zygophyllaceae, Syrian Rue; Cao et al., 2007). These compounds are of great interest due to their antitumor, antiviral, antimicrobial and antiparasitic activities (Kobayashi et al., 1994; Di Giorgio et al., 2004; Cao et al., 2007; Alomar et al., 2013). They are also recognized as photochemically active substances. Upon UVA photoexcitation, these alkaloids are able to photoinduce damage on biologically relevant macromolecules (Hazen and Gutierrez-Gonzalvez, 1988; Gonzalez et al., 2010, 2012a,b; Vignoni et al., 2013, 2014) as well as to inactivate bacteria and viruses (McKenna and Towers, 1981; Hudson et al., 1986).

It has been previously reported that, among six $\beta$ Cs tested, harmol exhibited the highest inhibitory effect on $P$. digitatum and B. cinerea (Olmedo et al., 2017). At a concentration of $1 \mathrm{mM}$, this full aromatic $\beta C$ provoked a complete germination inhibition of $B$. cinerea and $P$. digitatum conidia. For both pathogens, membrane permeabilization and significant reduction in conidia infectivity were detected. Thus, to characterize the antifungal activity of harmol against $P$. digitatum and $B$. cinerea, we investigated deleterious effects on several cellular features related to viability of conidia. The antifungal activity of harmol after UVA irradiation (i.e., photodynamic effect) was evaluated.

\section{MATERIALS AND METHODS}

\section{Chemicals, $\mathrm{p} K_{\mathrm{a}}$ Determination and Preparation of Stock Solutions}

Harmol from Sigma-Aldrich Co. (>98\%) was used without further purification. $\mathrm{p} K_{\mathrm{a}}$ values at room temperature were determined from changes in UV-vis absorption spectra of aqueous solutions of harmol, following the procedure described elsewhere (Cabrerizo et al., 2004). For antifungal assays, harmol stock solution was prepared in dimethyl sulfoxide (DMSO, Sigma-Aldrich Co.) and its concentration was calculated using the $\varepsilon_{320 \mathrm{~nm}}=18965 \mathrm{M}^{-1} \mathrm{~cm}^{-1}$, as previously described by Olmedo et al. (2017).

\section{Fungal Isolates, Growth Conditions, and Preparation of Conidial Suspension}

Fungal isolates were obtained from naturally infected fruit in Tucumán (Argentina). P. digitatum was isolated from lemons (Cerioni et al., 2009) and B. cinerea from blueberries (Olmedo et al., 2017). Both strains have been previously deposited with codes ICFC 842/15 and ICFC 841/15 in the IIB-INTECH collection of Fungal Cultures (ICFC, from the Laboratory of Mycology and Mushroom Cultivation, IIBINTECH, Chascomús, Argentina; WDCM data base reference: 826).

Fungal isolates were grown on potato dextrose agar (PDA) at $22 \pm 1^{\circ} \mathrm{C}$, in the dark for 10 or 7 days, in the case of P. digitatum or B. cinerea, respectively. B. cinerea sporulation was induced by placing a sterile wood stick onto the growing colony and incubating for further 7 days (Olmedo et al., 2017).

Preparation of conidial suspensions $\left(10^{6}\right.$ conidia $\left.\mathrm{mL}^{-1}\right)$ was performed as previously described (Cerioni et al., 2009). Dilution media was sterile distilled water at $\mathrm{pH} 5$, except for studies on effect of $\mathrm{pH}$.

\section{Antifungal Activity of Harmol at Different $\mathrm{pH}$}

Conidial suspensions were prepared in sodium acetate-acetic acid buffer ( $\mathrm{pH}$ 5) or Tris $\mathrm{HCl}$ buffer ( $\mathrm{pH}$ 9). These suspensions were incubated in the presence of $1 \mathrm{mM}$ harmol during $24 \mathrm{~h}$. Controls containing buffer and DMSO without harmol were included. After incubation, harmol was removed by centrifugation at $10000 \mathrm{rpm}$ for $10 \mathrm{~min}$ and replaced with the same volume of sterile distilled water. Five microliters of each suspension were spotted on PDA plates and colony formation was detected after $48 \mathrm{~h}$ of incubation. In addition, viability of conidia during treatments was evaluated, spreading serially diluted suspensions on PDA medium. Cell survival was quantified as colony forming units (CFU) $\mathrm{mL}^{-1}$ after 4 days of incubation at $22 \pm 1^{\circ} \mathrm{C}$.

\section{Ultrastructural Analysis of Conidia}

For ultrastructural characterization by transmission electron microscopy, conidia were incubated for $24 \mathrm{~h}$ with DMSO (control) or $1 \mathrm{mM}$ harmol. Afterward, samples were prepared as described by Cerioni et al. (2010). Observations were made with a Zeiss EM 109 transmission electron microscope from CIME (Centro Integral de Microscopía Electrónica, CONICET-UNT).

\section{Conidia Cell Wall Integrity Assay}

Conidial suspensions treated with $1 \mathrm{mM}$ harmol during $24 \mathrm{~h}$ were centrifuged and washed with sterile distilled water. Cell wall integrity was studied using the fluorescent dye Calcofluor White (CFW; Pringle, 1991), following a protocol adapted by Cerioni et al. (2010). Controls were performed in parallel, treating conidial suspensions with DMSO.

\section{Photodynamic Activity of Harmol}

The enhancing effect of UVA irradiation on antifungal activity of harmol was investigated as follows. P. digitatum and B. cinerea conidial suspensions were placed in a 96-well polystyrene 
microtiter plate containing harmol at several concentrations. The plate was irradiated during $30 \mathrm{~min}$ at $22^{\circ} \mathrm{C}$ with a Philips HPW $8 \mathrm{~W}$ lamp emitting at $365 \mathrm{~nm}$ (bandwidth $20 \mathrm{~nm}$ ). The dose rate at the irradiation site was $8 \mathrm{~W} / \mathrm{m}^{2}$ (Spectrosense $2+$ UV radiometer, Skye Instruments Ltd). A microplate containing identical treatments was placed at the same temperature, in the dark. After irradiation, both microplates were incubated during $24 \mathrm{~h}$ at $22^{\circ} \mathrm{C}$. CFU mL ${ }^{-1}$ were counted and the percentage of viability was determined (Muniz-Paredes et al., 2016).

\section{Determination of Reactive Oxygen Species (ROS) Production}

Conidial suspensions treated with harmol were irradiated or nonirradiated, as explained above. Control suspensions were treated with DMSO. After $24 \mathrm{~h}$ of incubation, suspensions were washed and resuspended in sterile distilled water. Reactive oxygen species (ROS) were determined with the $\mathrm{H}_{2}$ DCFDA probe (Davidson et al., 1996; Halliwell and Whiteman, 2004), following the protocol adapted by Cerioni et al. (2010).

$\mathrm{H}_{2} \mathrm{O}_{2}$ in situ detection in conidia was performed using the 3,3'-diaminobenzidine (DAB) uptake method (ThordalChristensen et al., 1997) with some modifications. Suspensions were exposed to $0.5 \mathrm{mg} \mathrm{mL} \mathrm{m}^{-1} \mathrm{DAB}$ solution and incubated during $8 \mathrm{~h}$ in the dark. Conidia were observed with a microscope Olympus IX51 equipped with an Olympus digital camera. A reddish-brown reaction product indicates $\mathrm{H}_{2} \mathrm{O}_{2}$ presence.

\section{Statistical Analysis}

All assays were performed three times, including three replicates for each condition. Data were subjected to analysis of variance followed by Tukey's test (Infostat, 2013 version, for Windows). Differences of $p$ value $\leq 0.05$ were considered significant.

\section{RESULTS}

\section{pH-Dependent Antifungal Activity of Harmol}

In aqueous solutions, in the $\mathrm{pH}$ range $2-13$, full aromatic $\beta \mathrm{Cs}$ show different acid-base equilibria (Gonzalez et al., 2009b). In the case of harmol, the most relevant equilibrium present under physiological $\mathrm{pH}$ involves the deprotonation of the pyridinic nitrogen $(\mathrm{N}-2)$, with an overall $\mathrm{p} K_{\mathrm{a}}$ value of 7.8 (Figure 1 ). This $\mathrm{p} K_{\mathrm{a}}$ value is in agreement, within the experimental error,

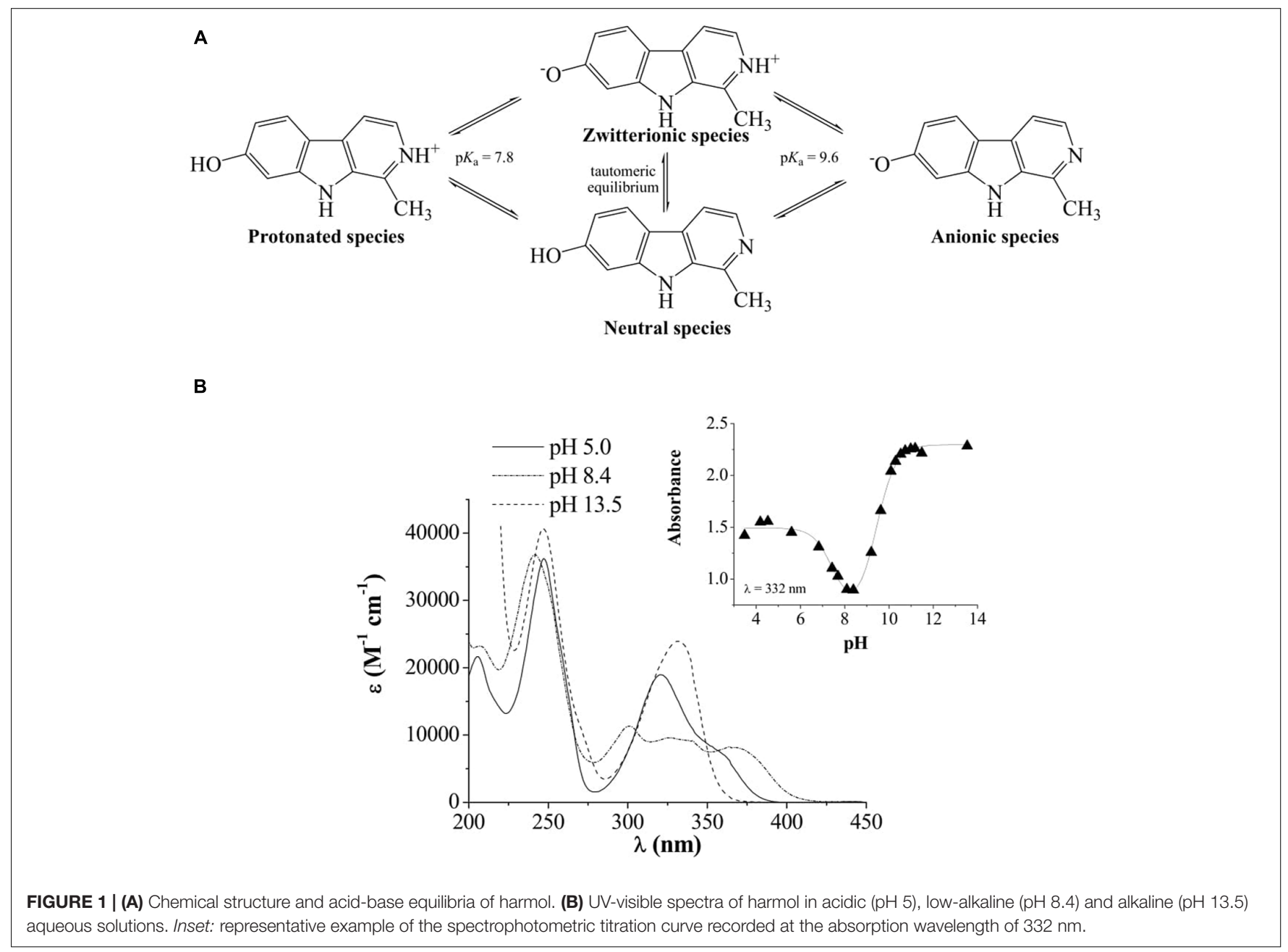


with the value previously reported (Tomas et al., 1985). The other functional groups, i.e., the hydroxy-substituent placed at position 7 and the nitrogen of the indole ring, have $\mathrm{p} K_{\mathrm{a}}$ values higher than 9.6. In order to ascertain the contribution of each physiologically relevant species (i.e., protonated and neutral) on the antifungal activity, the effect of $1 \mathrm{mM}$ harmol against $P$. digitatum and $B$. cinerea conidia was evaluated in acidic $(\mathrm{pH} 5$, where harmol is present at more than $99 \%$ in its protonated form) and alkaline $(\mathrm{pH} 9$, where a mixture of neutral, zwitterionic and anionic species of harmol is present) conditions (Figures $2 \mathrm{~A}, \mathbf{B}$ ). After $24 \mathrm{~h}$ of incubations with harmol at $\mathrm{pH}$ 9, CFU $\mathrm{mL}^{-1}$ remained unchanged for both pathogens. In contrast, at $\mathrm{pH} 5$, harmol protonated species exhibited a significant antimicrobial effect. $P$. digitatum $\mathrm{CFU} \mathrm{mL}^{-1}$ counts were twofold reduced compared to controls, while $B$. cinerea exhibited a complete loss of viability.

\section{Modifications in Ultrastructure of Conidia by Harmol}

Figure 3 shows TEM photomicrographs of $P$. digitatum and B. cinerea conidia treated with $1 \mathrm{mM}$ harmol during $24 \mathrm{~h}$. Almost all treated conidia exhibited unclear nuclei structures and disordered cytoplasms, revealing a severe cellular damage (Figures 3B,E,F). In some cases, significant distortion of the cell shape and/or loss of intracellular content were observed (Figures 3C,F). Samples of B. cinerea conidia treated with harmol exhibited cellular debris, indicating lysis (Figures 3E,F). In contrast, for both phytopathogens, conidia in control treatments

\section{A}

$\frac{P . \text { digitatum }}{\text { control DMSO harmol }} \quad$ control DMSO harmol

pH 5
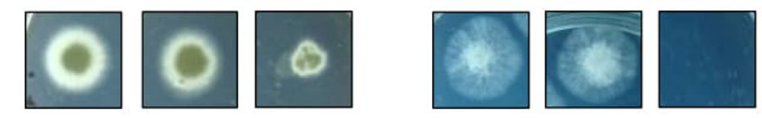

pH 9
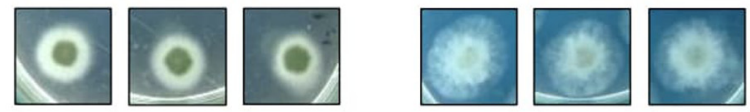

B

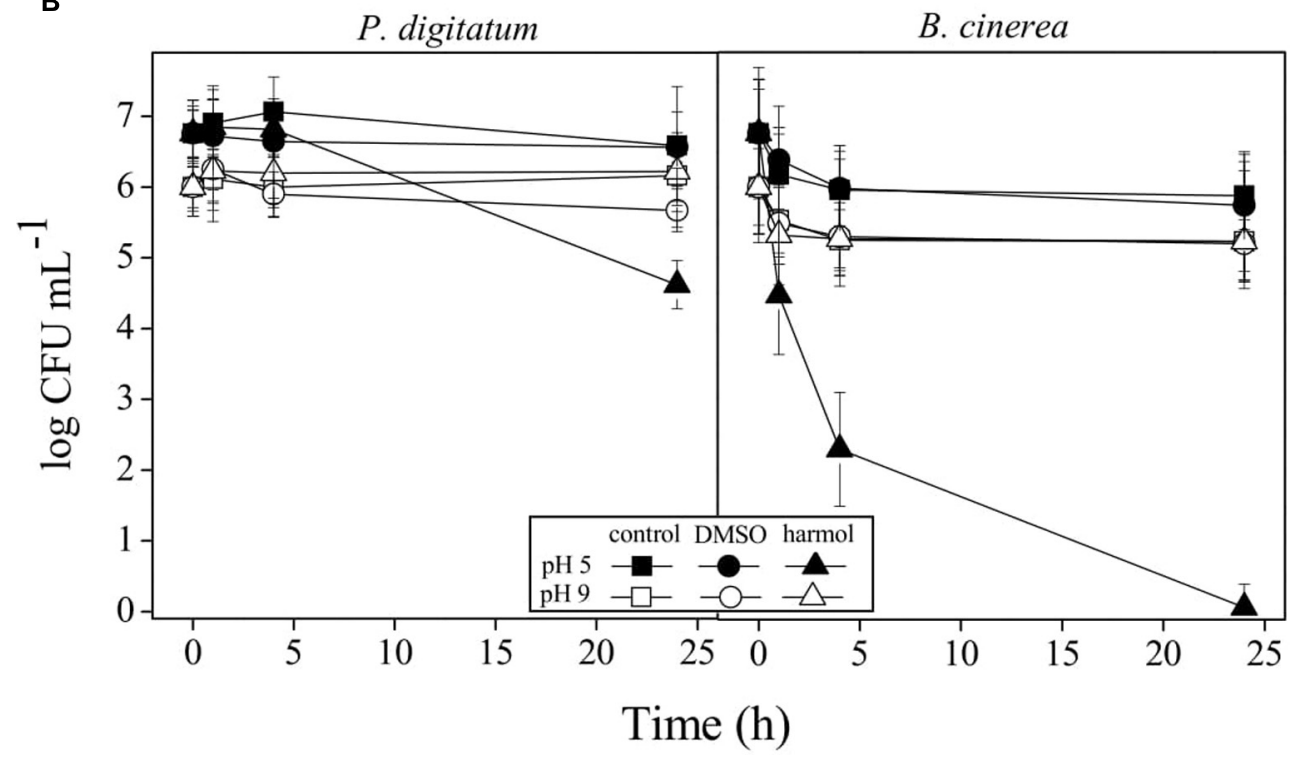

FIGURE 2 | Effect of $\mathrm{pH}$ on antifungal activity of harmol. $P$. digitatum and $B$. cinerea conidia were treated for $24 \mathrm{~h}$ with $1 \mathrm{mM}$ harmol at the indicated $\mathrm{pH}$. Controls with or without DMSO were included. (A) After treatments, colony formation was assessed using PDA plates incubated for $48 \mathrm{~h}$. Photographs are representative of three independent experiments. (B) Viability of conidia was determined by counting CFU mL-1 at the indicated times during the treatments with harmol. Three independent experiments were performed. 


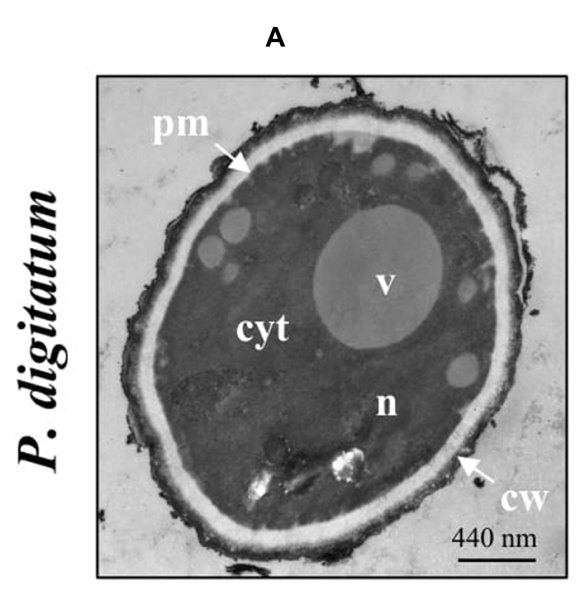

B
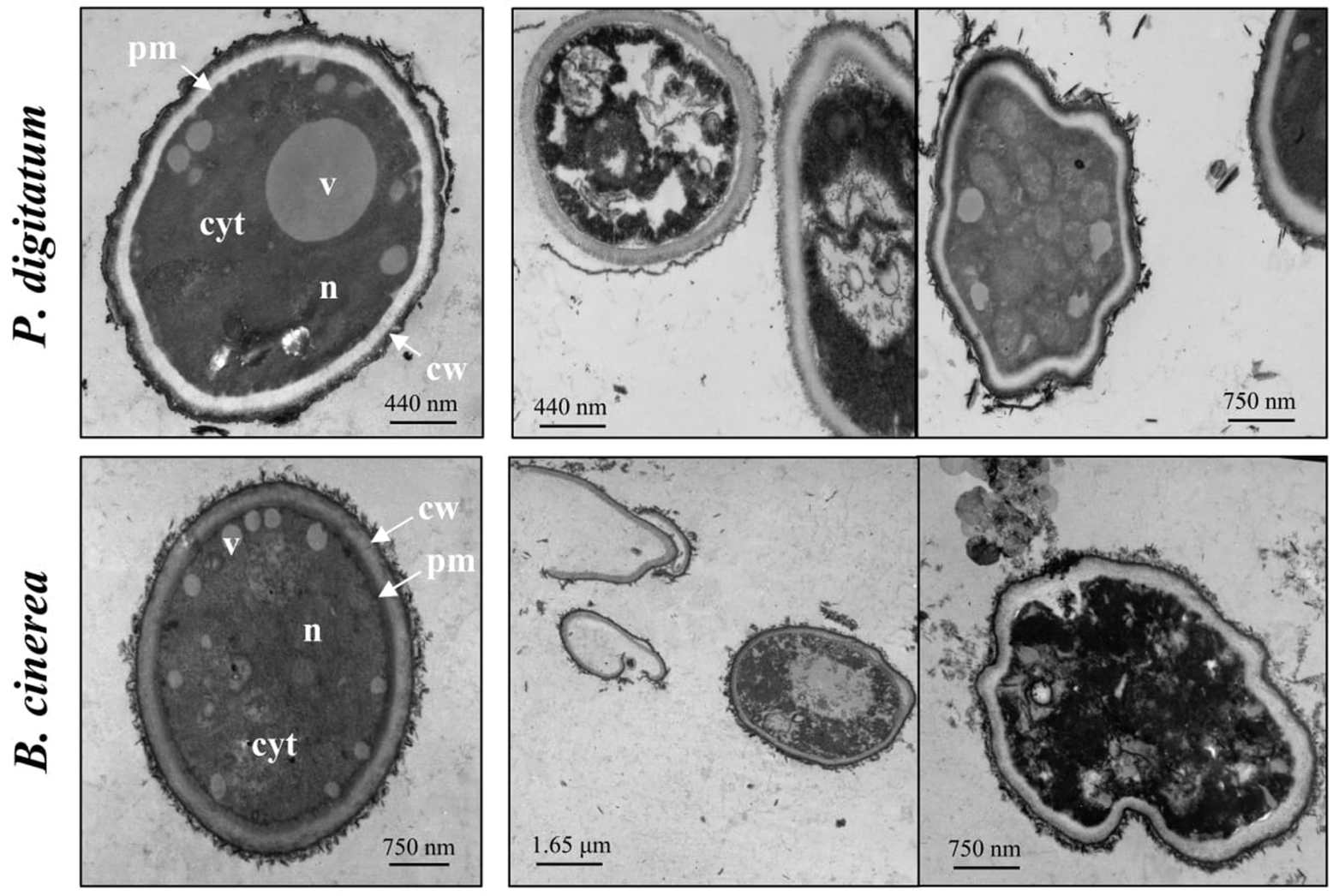

D

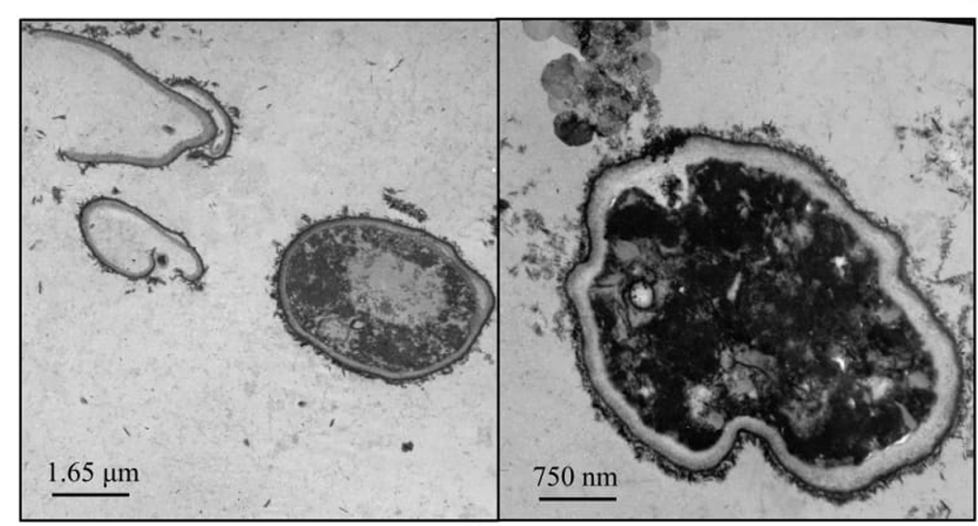

E

$\mathbf{F}$

FIGURE 3 | Effect of harmol on ultrastructure of conidia. Transmission electron micrographs of the indicated pathogens: (A,D) conidia in control treatment; (B,C,E,F) conidia treated with $1 \mathrm{mM}$ harmol. Photographs are representative of three independent experiments. cyt, cytoplasm; $\mathrm{v}$, vacuole; $\mathrm{n}$, nucleus; pm, plasmatic membrane; cw, cell wall.

showed a well-organized cytoplasm, nuclei, and visible vacuoles surrounded by well-defined envelopes (Figures 3A,D).

Figure 4 shows fluorescence and light microscopy images of CFW stained cells. Conidia treated with harmol exhibited a stronger CFW fluorescence pattern on cell surface (Figures 4B,D) compared with the untreated controls (Figures 4A,C). In addition, bright spots were frequent throughout $B$. cinerea conidia treated with harmol (Figure 4D, inset).

\section{Enhancement of Antifungal Activity of Harmol by UVA Photoactivation}

Some $\beta C$ alkaloids have been described as efficient photosensitizers in acidic conditions (Gonzalez et al., 2009b, 2012a). Thus, toxicity of electronically photoexcited harmol was screened at $\mathrm{pH}$, exposing the treatments to UVA irradiation (Table 1). The decrease in viability achieved in 30 min-irradiated treatments was different between both fungi, being $B$. cinerea the most sensitive. For this phytopathogen, photosensitized treatment required half of the harmol concentration to reach the same inhibitory effect compared to the non-irradiated counterpart treatment. Moreover, UVA irradiation in the presence of $0.1,0.2$ and $0.3 \mathrm{mM}$ harmol, provoked a significant decrease in conidia survival. In respect to $P$. digitatum, dark and irradiated treatments resulted on viability of 1.15 and $0.5 \%$, respectively. It is worth to note that conidia viability of both pathogens was not altered by a 30 min irradiation with UVA in the absence of harmol (data not shown).

\section{ROS Accumulation after Incubation with Harmol}

Intracellular ROS production was studied in conidia incubated

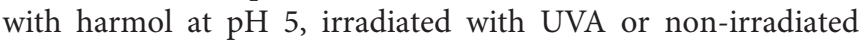
(Figure 5). For $P$. digitatum, the intracellular ROS content in non-irradiated treatments was similar to that of the controls (Figure 5A). In photoactivated treatments, a significant ROS accumulation was observed in conidia exposed to the highest harmol concentration $(1 \mathrm{mM})$. In respect to $B$. cinerea, the exposure to harmol in the dark led to six- to eight-fold increments in the ROS production compared to controls without harmol. Furthermore, ROS production in $B$. cinerea conidia treated with photoactivated harmol was over 15 times higher than that of controls. 


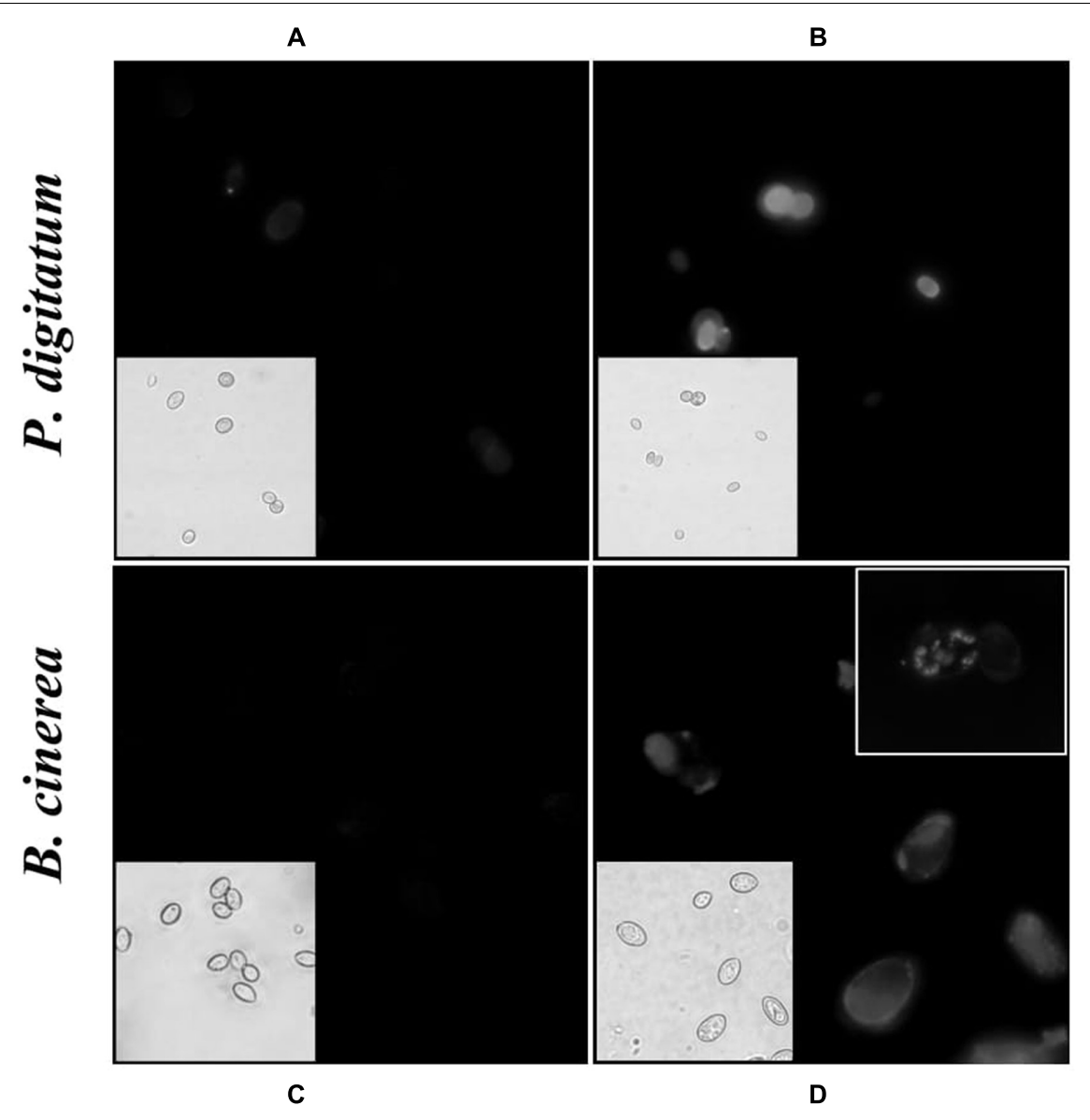

FIGURE 4 | Effect of harmol on integrity of the cell wall. Conidia were exposed to $1 \mathrm{mM}$ harmol during $24 \mathrm{~h}$ and incubated with CFW. Fluorescence microscopy images $(100 \times)$ of conidia in control treatment $\mathbf{( A , C )}$, and treated conidia (B,D). The corresponding light microscopy images are shown for each panel. Photographs are representative of three independent experiments.

TABLE 1 | Photodynamic effect of harmol on viability of conidia.

\begin{tabular}{|c|c|c|c|c|}
\hline \multirow[b]{3}{*}[\mathrm{mM}]{} & \multicolumn{4}{|c|}{ Viability (\%) } \\
\hline & \multicolumn{2}{|c|}{ P. digitatum } & \multicolumn{2}{|c|}{ B. cinerea } \\
\hline & harmol & harmol + UVA & harmol & harmol + UVA \\
\hline- & $100.00^{a}$ & $100.00^{a}$ & $100.00^{a}$ & $100.00^{a}$ \\
\hline 0.1 & $97.40^{a}$ & $100.00^{a}$ & $63.80^{b}$ & $6.80^{b \#}$ \\
\hline 0.2 & $95.50^{a}$ & $83.20^{c}$ & $7.70^{c}$ & $1.50^{\mathrm{c \#}}$ \\
\hline 0.3 & $84.20^{a}$ & $88.80^{b}$ & $1.20^{d}$ & $0.20 \mathrm{d \#}$ \\
\hline 0.5 & $8.30^{b}$ & $1.00^{\mathrm{d} \#}$ & $0.02^{d}$ & $0.00^{d}$ \\
\hline 1.0 & $1.50^{b}$ & $0.50^{d \#}$ & $0.00^{d}$ & $0.00^{d}$ \\
\hline
\end{tabular}

Letters indicate significant differences $(p \leq 0.05)$ within columns. \# indicates significant differences $(p \leq 0.05)$ between irradiated and non-irradiated treatments with the same harmol concentration.

A significant $\mathrm{DAB}$ staining was observed in $B$. cinerea conidia treated with harmol, which indicates $\mathrm{H}_{2} \mathrm{O}_{2}$ accumulation (Figure 5B). Pigmentation was more evident when suspensions were exposed to UVA. In contrast, a lack of pigmentation in $P$. digitatum conidia was observed in all treatments, except in the conidial suspension treated with $1 \mathrm{mM}$ harmol and exposed to UVA.

\section{DISCUSSION}

Harmol has antimicrobial properties against $P$. digitatum and B. cinerea (Olmedo et al., 2017). The exposure to this compound inhibited germination, mycelial growth, sporulation and residual infectivity of these microorganisms. In the present work, we characterized antifungal activity of harmol in terms of $\mathrm{pH}$ and conidial targets. An enhancement of harmol toxicity was achieved by photodynamic effect.

Our results indicate that antifungal activity of harmol strongly depends on $\mathrm{pH}$. Protonated harmol was active against both phytopathogens, while the neutral, zwitterionic and/or anionic species lacked inhibitory ability. We consider that the interaction between harmol in its cationic form and the negatively charged microbial surfaces is probable to occur. In agreement, cationic species guides antimicrobial properties of different molecules (Boman, 1994; Ladokhin et al., 1997; Matsuzaki et al., 1997; Muñoz et al., 2006). In addition, it has been reported that changes 
A

P. digitatum B. cinerea
B

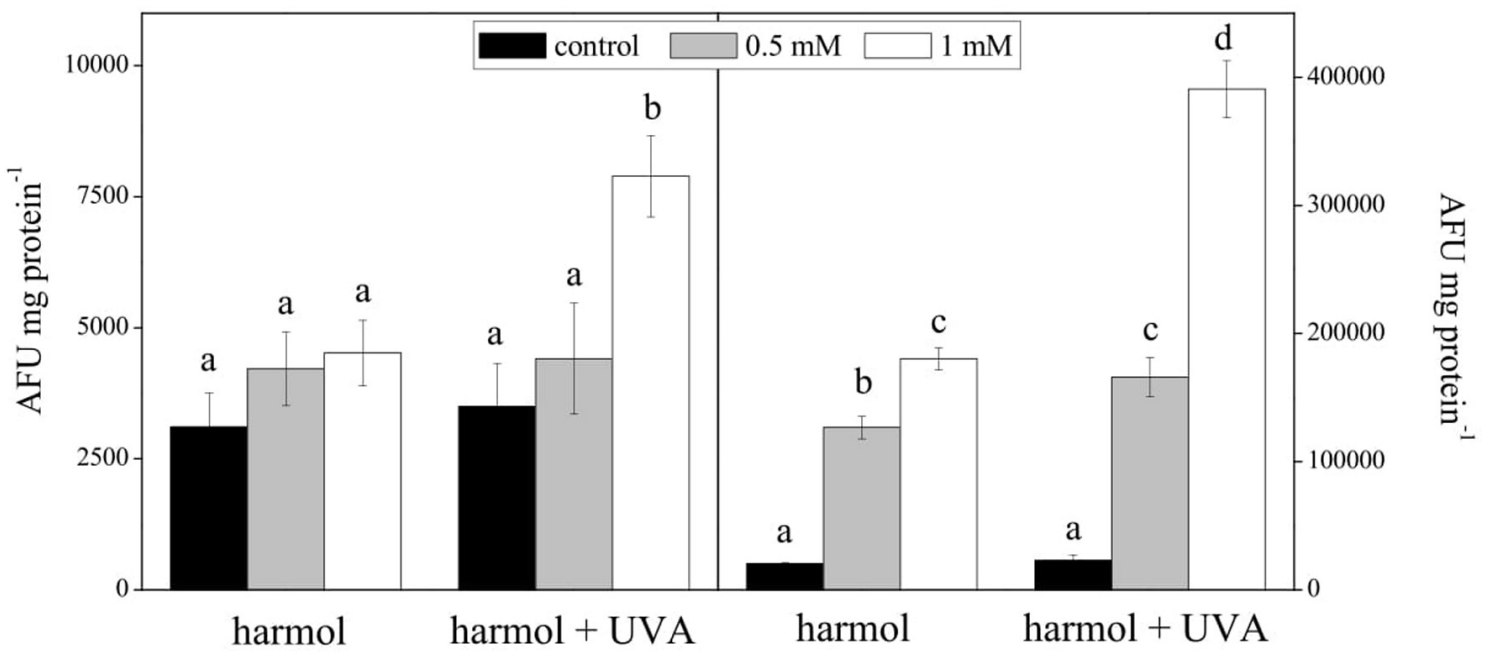

B

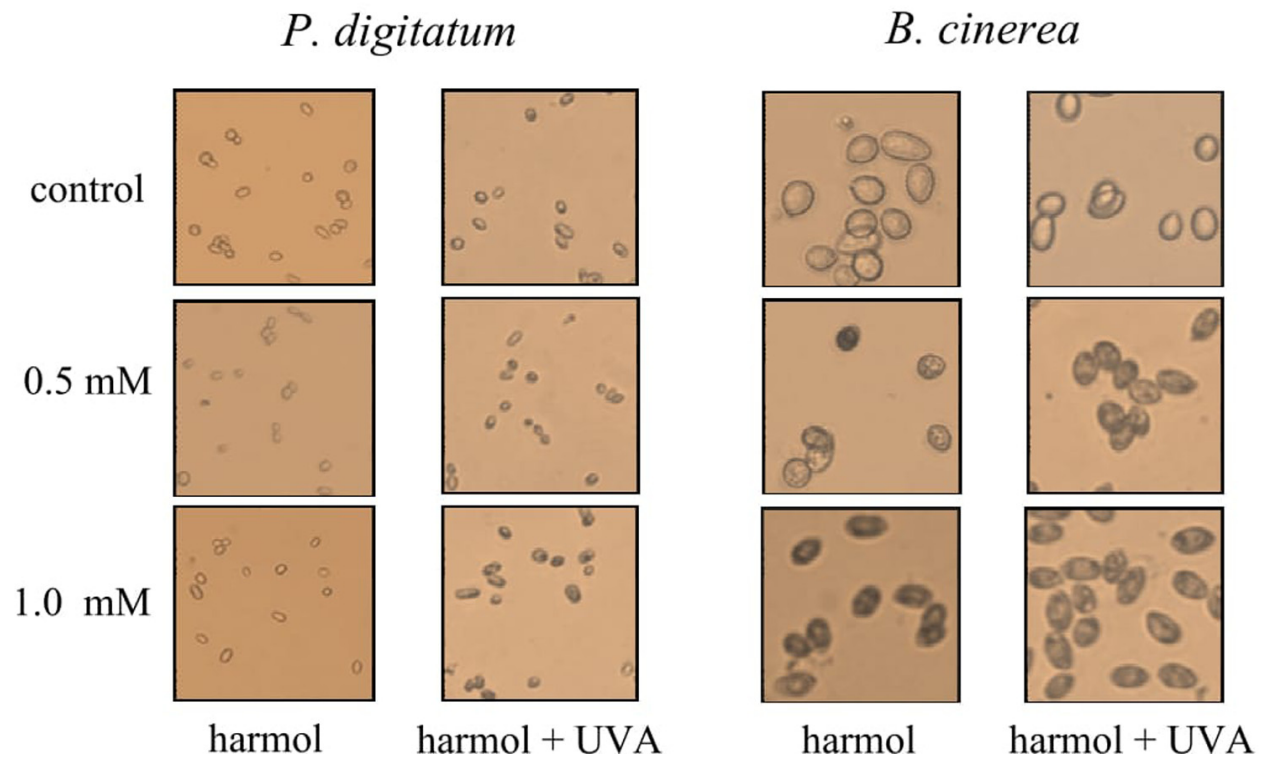

FIGURE 5 | Effect of harmol on production of intracellular ROS. Conidia were treated with harmol at the indicated concentrations, and irradiated or non-irradiated with UVA. (A) ROS quantification using the $\mathrm{H}_{2}$ DCFDA fluorescent probe. Data are the average \pm SD of three experiments. For each pathogen, different letters indicate significant differences among treatments. AFU, arbitrary fluorescence units. (B) $\mathrm{H}_{2} \mathrm{O}_{2}$ in situ detection by staining with $3,3^{\prime}$-diaminobenzidine (DAB). Light microscopy photographs $(40 \times)$ are representative of three independent experiments. $\mathrm{H}_{2} \mathrm{O}_{2}$ accumulation is visualized as dark conidia.

in $\beta$ Cs electronic ground state distribution at different $\mathrm{pH}$ have a strong effect on chemical and binding properties of these compounds (Gonzalez et al., 2010, 2012a,b, 2014; Vignoni et al., 2013).

We have previously demonstrated that harmol at $\mathrm{pH} 5$ induces membrane permeabilization in $P$. digitatum and $B$. cinerea cells (Olmedo et al., 2017). In CFW staining assays, performed at the same $\mathrm{pH}$, bright spots and fluorescence increment were observed in harmol treated conidia. This suggests that cell wall integrity was altered, leading to the exposure of chitin, the main structural polysaccharide of internal wall. Namely, the fluorescence increment might be explained by the modification or loss in the outermost cell surface proteins, which expose internal cell wall components (Kubitschek-Barreira et al., 2013; 
Huang et al., 2016). Moreover, when conidia treated with harmol were observed by TEM, the most evident effect was wall distortion, with the consequent leak of cytoplasmic content at least in $B$. cinerea. It has been previously reported that dissolution or perturbation of wall structural polymers have adverse effects upon growth and differentiation of fungi (Poulose, 1992; Lorito et al., 1994; Soylu et al., 2007, 2010).

Previous reports stated that, upon UV light irradiation, $\beta C s$ exhibit phototoxic properties (McKenna and Towers, 1981; Mori et al., 1998; Cao et al., 2007). Antifungal activity of harmol was severely improved when treatments were irradiated with UVA. In our irradiated approach, the complete inhibition of $B$. cinerea was achieved with lower concentrations compared to non-irradiated treatments. The eradication of this pathogen is important because $B$. cinerea causes disease at very low inoculum levels. For instance, it has been reported that tomato stems can be infected with only 10 conidia applied to the surface (O'Neill et al., 1997). On the other hand, $10^{3} \mathrm{P}$. digitatum conidia $\mathrm{mL}^{-1}$ remained viable after irradiated treatments. Nevertheless, this inoculum might be unable to infect fruit, considering data in our previous work (Olmedo et al., 2017). Our study provides useful knowledge for the design of novel antifungal compounds based on $\beta$ Cs skeleton, with a distinctive photodynamic behavior.

High ROS values in $B$. cinerea treated with harmol in nonirradiated condition agrees with the detected fungicidal action. In respect to $P$. digitatum, ROS accumulation did not occur, which is in accordance with the fungistatic effect previously reported (Olmedo et al., 2017). When conidia were irradiated in the presence of harmol, ROS production was enhanced for both phytopathogens with the consequent loss of viability. The ability of some $\beta C$ s to generate ROS under UVA irradiation has been previously reported (Gonzalez et al., 2009b). It was proposed that $\mathrm{H}_{2} \mathrm{O}_{2}$ is formed by electron transfer to $\mathrm{O}_{2}$ yielding the superoxide anion $\left(\mathrm{O}_{2}{ }^{\bullet-}\right)$ and its spontaneous disproportionation to $\mathrm{H}_{2} \mathrm{O}_{2}$. Mechanistically, photodynamic effects can be a consequence of a direct reaction of the excited state of the photosensitizer with biomolecules and/or structural constituents of the fungi (i.e.,

\section{REFERENCES}

Alomar, M. L., Rasse-Suriani, F. A., Ganuza, A., Coceres, V. M., Cabrerizo, F. M., and Angel, S. O. (2013). In vitro evaluation of beta-carboline alkaloids as potential anti-Toxoplasma agents. BMC Res. Notes 6:193. doi: 10.1186/17560500-6- 193

Boman, H. G. (1994). Antimicrobial peptides. Chairman's opening remarks. Ciba Found. Symp. 186, 1-4.

Cabrerizo, F. M., Thomas, A. H., Lorente, C., Dántola, M. L., Petroselli, G., ErraBalsells, R., et al. (2004). Generation of reactive oxygen species during the photolysis of 6-(Hydroxymethyl)pterin in alkaline aqueous solutions. Helv. Chim. Acta 87, 349-365. doi: 10.1002/hlca.200490032

Cao, R., Peng, W., Wang, Z., and Xu, A. (2007). beta-Carboline alkaloids: biochemical and pharmacological functions. Curr. Med. Chem. 14, 479-500. doi: 10.2174/092986707779940998

Cerioni, L., Rapisarda, V. A., Hilal, M., Prado, F. E., and Rodriguez-Montelongo, L. (2009). Synergistic antifungal activity of sodium hypochlorite, hydrogen peroxide, and cupric sulfate against Penicillium digitatum. J. Food Prot. 72, 1660-1665. doi: 10.4315/0362-028X-72.8.1660
Type-I reactions) or indirectly via ROS (i.e., Type-II reactions; Foote, 1991). Previous findings for other $\beta C$ derivatives suggest that Type I reactions seem to be responsible for the damage generation (Gonzalez et al., 2010, 2012a). In the case of harmol, a similar pattern would be expected as the most probable mechanism of action. However, in view of our results, the Type-II reactions should not be discarded.

Taken together, our data suggest that the antifungal action of harmol may begin with electrostatic interactions between the protonated $\beta C$ and conidial surface, which leads to the alteration of envelopes integrity, increment in ROS production, morphological damage, and cell collapse. UVA photoactivation improves the fungicidal action of harmol, allowing a decrease in the effective doses. The mode of action and the multiple cellular targets that may be affected by the drug prevent the appearance of resistant fungal strains. The combination of chemo- and photodynamic therapies represents an effective treatment to inactivate microorganisms. The use of harmol in the design of antifungals absorbing in the far UVA could be a good alternative for both, pre-harvest treatments (considering the sun as an UVA source) and post-harvest treatments (including UVA lamps in packing houses).

\section{AUTHOR CONTRIBUTIONS}

GO, LC, MG, FC, SV, and VR designed the experiments. GO, LC, and MG performed the experiments. GO, LC, MG, FC, SV, and VR analyzed the data. GO, FC, SV, and VR drafted the manuscript. All authors read and approved the final manuscript.

\section{ACKNOWLEDGMENTS}

The present work was partially supported by ANPCyT (PICT 2012-2838, 2013-2536, and 2014-2856), and UNT (PIUNT 26/D530). GO is a fellow from CONICET. LC, MG, FC, SV, and VR are research members of CONICET.

Cerioni, L., Volentini, S. I., Prado, F. E., Rapisarda, V. A., and RodriguezMontelongo, L. (2010). Cellular damage induced by a sequential oxidative treatment on Penicillium digitatum. J. Appl. Microbiol. 109, 1441-1449. doi: 10.1111/j.1365-2672.2010.04775.x

Davidson, J. F., Whyte, B., Bissinger, P. H., and Schiestl, R. H. (1996). Oxidative stress is involved in heat-induced cell death in Saccharomyces cerevisiae. Proc. Natl. Acad. Sci. U.S.A. 93, 5116-5121. doi: 10.1073/pnas.93.10.5116

Di Giorgio, C., Delmas, F., Ollivier, E., Elias, R., Balansard, G., and Timon-David, P. (2004). In vitro activity of the beta-carboline alkaloids harmane, harmine, and harmaline toward parasites of the species Leishmania infantum. Exp. Parasitol. 106, 67-74. doi: 10.1016/j.exppara.2004.04.002

Elad, Y., and Evensen, K. (1995). Physiological aspects of resistance to Botrytis cinerea. Phytopathology 85, 637-643. doi: 10.1094/phyto-85-637

Foote, C. S. (1991). Definition of type I and type II photosensitized oxidation. Photochem. Photobiol. 54, 659. doi: 10.1111/j.1751-1097.1991.tb02071.x

Gatto, M., Ippolito, A., Linsalata, V., Cascarano, N., Nigro, F., Vanadia, S., et al. (2011). Activity of extracts from wild edible herbs against postharvest fungal diseases of fruit and vegetables. Postharvest Biol. Technol. 61, 72-82. doi: 10.1016/j.postharvbio.2011.02.005 
Gonzalez, M. M., Arnbjerg, J., Denofrio, M. P., Erra-Balsells, R., Ogilby, P. R., and Cabrerizo, F. M. (2009a). One- and two-photon excitation of betacarbolines in aqueous solution: $\mathrm{pH}$-dependent spectroscopy, photochemistry, and photophysics. J. Phys. Chem. A 113, 6648-6656. doi: 10.1021/jp90 $2105 \mathrm{x}$

Gonzalez, M. M., Denofrio, M. P., Garcia Einschlag, F. S., Franca, C. A., Pis Diez, R., Erra-Balsells, R., et al. (2014). Determining the molecular basis for the pH-dependent interaction between 2'-deoxynucleotides and 9H-pyrido[3,4b]indole in its ground and electronic excited states. Phys. Chem. Chem. Phys. 16, 16547-16562. doi: 10.1039/c4cp01910e

Gonzalez, M. M., Pellon-Maison, M., Ales-Gandolfo, M. A., Gonzalez-Baro, M. R., Erra-Balsells, R., and Cabrerizo, F. M. (2010). Photosensitized cleavage of plasmidic DNA by norharmane, a naturally occurring beta-carboline. Org. Biomol. Chem. 8, 2543-2552. doi: 10.1039/c002235g

Gonzalez, M. M., Rasse-Suriani, F. A. O., Franca, C. A., Pis Diez, R., Gholipour, Y., Nonami, H., et al. (2012a). Photosensitized electron transfer within selfassembled norharmane-2'-deoxyadenosine 5'-monophosphate (dAMP) complex. Org. Biomol. Chem. 10, 9359-9372. doi: 10.1039/c2ob26462e

Gonzalez, M. M., Salum, M. L., Gholipour, Y., Cabrerizo, F. M., and ErraBalsells, R. (2009b). Photochemistry of norharmane in aqueous solution. Photochem. Photobiol. Sci. 8, 1139-1149. doi: 10.1039/b822173a

Gonzalez, M. M., Vignoni, M., Pellon-Maison, M., Ales-Gandolfo, M. A., Gonzalez-Baró, M. R., Erra-Balsells, R., et al. (2012b). Photosensitization of DNA by $\beta$-carbolines: kinetic analysis and photoproducts characterization. Org. Biomol. Chem. 10, 1807-1819. doi: 10.1039/c2ob06505c

Grayer, R. J., and Kokubun, T. (2001). Plant-fungal interactions: the search for phytoalexins and other antifungal compounds from higher plants. Phytochemistry 56, 253-263. doi: 10.1016/S0031-9422(00)00450-7

Halliwell, B., and Whiteman, M. (2004). Measuring reactive species and oxidative damage in vivo and in cell culture: how should you do it and what do the results mean? Br. J. Pharmacol. 142, 231-255.

Hazen, M. J., and Gutierrez-Gonzalvez, M. G. (1988). UV-mediated toxic bioactivity of harmine in the meristematic cells of Allium cepa. Mutagenesis 3, 333-335. doi: 10.1093/mutage/3.4.333

Holmes, G. J., and Eckert, J. W. (1999). Sensitivity of Penicillium digitatum and P. italicum to postharvest Citrus fungicides in California. Phytopathology 89, 716-721. doi: 10.1094/PHYTO.1999.89.9.716

Huang, L., Zhang, J., Song, T., Yuan, L., Zhou, J., Yin, H., et al. (2016). Antifungal curcumin promotes chitin accumulation associated with decreased virulence of Sporothrix schenckii. Int. Immunopharmacol. 34, 263-270. doi: 10.1016/j. intimp.2016.03.010

Hudson, J. B., Graham, E. A., and Towers, G. H. (1986). Antiviral effect of harmine, a photoactive beta-carboline alkaloid. Photochem. Photobiol. 43, 21-26. doi: 10.1111/j.1751-1097.1986.tb05586.x

Kobayashi, J., Tsuda, M., Kawasaki, N., Sasaki, T., and Mikami, Y. (1994). 6Hydroxymanzamine A and 3,4-dihydromanzamine A, new alkaloids from the Okinawan marine sponge Amphimedon Sp. J. Nat. Prod. 57, 1737-1740. doi: $10.1021 / \mathrm{np} 50114 \mathrm{a} 021$

Kubitschek-Barreira, P., Curty, N., Neves, G., Gil, C., and Lopes-Bezerra, L. (2013). Differential proteomic analysis of Aspergillus fumigatus morphotypes reveals putative drug targets. J. Proteom. 78, 522-534. doi: 10.1016/j.jprot.2012. 10.022

Ladokhin, A. S., Selsted, M. E., and White, S. H. (1997). Bilayer interactions of indolicidin, a small antimicrobial peptide rich in tryptophan, proline, and basic amino acids. Biophys. J. 72, 794-805. doi: 10.1016/S0006-3495(97)78713-7

Latorre, B., Flores, V., Sara, A., and Roco, A. (1994). Dicarboximideresistant strains of Botrytis cinerea from table grapes in Chile: survey and characterization. Plant Dis. 78, 990-994. doi: 10.1094/PD-78-0990

Lorito, M., Peterbauer, C., Hayes, C. K., and Harman, G. E. (1994). Synergistic interaction between fungal cell wall degrading enzymes and different antifungal compounds enhances inhibition of spore germination. Microbiology 140, 623-629. doi: 10.1099/00221287-140-3-623

Matsuzaki, K., Sugishita, K., Harada, M., Fujii, N., and Miyajima, K. (1997). Molecular action mechanisms and membrane recognition of membrane-acting antimicrobial peptides. Yakugaku Zasshi 1327, 119-130.

McKenna, D. J., and Towers, G. H. N. (1981). Ultra-violet mediated cytotoxic activity of $\beta$-carboline alkaloids. Phytochemistry 20, 1001-1004. doi: 10.1016/ 0031-9422(81)83017-8
Mori, T., Nakagawa, A., Kobayashi, N., Hashimoto, M. W., Wakabayashi, K., Shimoi, K., et al. (1998). 3-Amino-1,4-dimethyl-5H-pyrido[4,3-b]indole (Trp$\mathrm{P}-1$ ) sensitizes mammalian cells to UV radiation by causing the S-phase arrest, not by inhibiting the repair of DNA damage as observed in Escherichia coli. J. Radiat. Res. 39, 21-33. doi: 10.1269/jrr.39.21

Muniz-Paredes, F., Garza-Lopez, P. M., Viniegra-Gonzalez, G., and Loera, O. (2016). Comparison between superficial and solid-state cultures of Isaria fumosorosea: conidial yields, quality and sensitivity to oxidant conditions. World J. Microbiol. Biotechnol. 32, 111. doi: 10.1007/s11274-016-2072-x

Muñoz, A., López-Garcia, B., and Marcos, J. (2006). Studies on the mode of action of the antifungal hexapeptide PAF 26. Antimicrob. Agents Chemother. 50, 3847-3855. doi: 10.1128/AAC.00650-06

Olmedo, G. M., Cerioni, L., Gonzalez, M. M., Cabrerizo, F. M., Rapisarda, V. A., and Volentini, S. I. (2017). Antifungal activity of b-carbolines on Penicillium digitatum and Botrytis cinerea. Food Microbiol. 62, 9-14. doi: 10.1016/j.fm.2016. 09.011

O’Neill, T. M., Shtienberg, D., and Elad, Y. (1997). Effect of some host and microclimate factors on infection of tomato stems by Botrytis cinerea. Plant Dis. 81, 36-40. doi: 10.1094/PDIS.1997.81.1.36

Palou, L., Usall, J., Munoz, J., Smilanick, J., and Viñas, I. (2002). Hot water, sodium bicarbonate and sodium carbonate for the control of green and blue mold of Clemetine mandarins. Postharvest Biol. Technol. 24, 93-96. doi: 10.1016/S09255214(01)00178-8

Poulose, A. (1992). "Biotechnology and fungal control," in Target Sites of Fungicide Action, ed. W. Koller (Boca Raton, FL: CRC), 311-318.

Pringle, J. R. (1991). Staining of bud scars and other cell wall chitin with calcofluor. Methods Enzymol. 194, 732-735. doi: 10.1016/0076-6879(91)94055-H

Sayago, J., Ordóñez, R., Negrillo Kovacevich, L., Torres, S., and Isla, M. (2012). Antifungal activity of extracts of extremophile plants from the Argentine Punato control citrus postharvest pathogens and green mold. Postharvest Biol. Technol. 67, 19-24. doi: 10.1016/j.postharvbio.2011.12.011

Soylu, E. M., Kurt, S., and Soylu, S. (2010). In vitro and in vivo antifungal activities of the essential oils of various plants against tomato grey mould disease agent Botrytis cinerea. Int. J. Food Microbiol. 143, 183-189. doi: 10.1016/j.ijfoodmicro. 2010.08.015

Soylu, S., Yigitbas, H., Soylu, E. M., and Kurt, S. (2007). Antifungal effects of essential oils from oregano and fennel on Sclerotinia sclerotiorum. J. Appl. Microbiol. 103, 1021-1030. doi: 10.1111/j.1365-2672.2007.03310.x

Thordal-Christensen, H., Zhang, Z., Wei, Y., and Collinge, D. B. (1997). Subcellular localization of $\mathrm{H} 2 \mathrm{O} 2$ in plants: $\mathrm{H} 2 \mathrm{O} 2$ accumulation in papillae and hypersensitive response during the barley-powdery mildew interaction. Plant $J$. 11, 1187-1194. doi: 10.1046/j.1365-313X.1997.11061187.x

Tomas, F., Zabala, I., and Olba, A. (1985). Acid-base and tautomeric equilibria of harmol in the ground and first excited singlet states. J. Photochem. 31, 253-263. doi: 10.1016/0047-2670(85)85094-2

Vignoni, M., Erra-Balsells, R., Epe, B., and Cabrerizo, F. M. (2014). Intra- and extra-cellular DNA damage by harmine and 9-methyl-harmine. J. Photochem. Photobiol. B 132, 66-71. doi: 10.1016/j.jphotobiol.2014.01.020

Vignoni, M., Rasse-Suriani, F. A., Butzbach, K., Erra-Balsells, R., Epe, B., and Cabrerizo, F. M. (2013). Mechanisms of DNA damage by photoexcited 9methyl-beta-carbolines. Org. Biomol. Chem. 11, 5300-5309. doi: 10.1039/ c3ob40344k

Conflict of Interest Statement: The authors declare that the research was conducted in the absence of any commercial or financial relationships that could be construed as a potential conflict of interest.

The reviewer RT and handling Editor declared their shared affiliation and the handling Editor states that the process nevertheless met the standards of a fair and objective review.

Copyright () 2017 Olmedo, Cerioni, González, Cabrerizo, Volentini and Rapisarda. This is an open-access article distributed under the terms of the Creative Commons Attribution License (CC BY). The use, distribution or reproduction in other forums is permitted, provided the original author(s) or licensor are credited and that the original publication in this journal is cited, in accordance with accepted academic practice. No use, distribution or reproduction is permitted which does not comply with these terms. 